\title{
Implementation of GIS-Based Applications in Water Governance
}

\author{
Rebecca Moody • Jacko A. van Ast
}

Received: 5 October 2010 /Accepted: 29 September 2011 /

Published online: 13 October 2011

(C) The Author(s) 2011. This article is published with open access at Springerlink.com

\begin{abstract}
Geographical Information Systems (GIS) are computer programs that are able to bring large amounts of data of both the physical and the social system together in one comprehensive overview shown digitally. GIS occurred very rapidly on the Dutch policy agenda. In this paper we analyze how the fast introduction process of GIS-based instruments in water management and more specifically in river flood management can be explained. By applying a range of classical models on agenda-setting, we show the important contribution of GIS to the water and flood issue in current spatial planning and policy development in the Netherlands.
\end{abstract}

Keywords Water management · Flood management - GIS applications · Agenda setting · Water Policy $\cdot$ Water governance

\section{Introduction}

In many policy areas Geographical Information Systems (GIS), ICT that allows visualisation of spatial (physical and social) entities in a geographical map, are rapidly introduced. The - compared to other policy innovations - high speed of these introductions can be explained by different factors. Knowing these factors can help policy-makers with future policy implementation processes. In the following we will search for these factors.

Our cases are selected from the field of water management, a field that recently experienced a fundamental change in approach. After a period in which different sectors attached to the functions of the water system all had their own separate policy field, integration became the leading principle (Saeijs 1991). In the newest 'ecological' or 'adaptive environmental management' approach, governments together with stakeholders aim to adapt societal demands to the processes in ecosystems (Holling 1973; Allen et al. 1992; Ollsson et al. 2004; Hooper 2005). The concept can be characterized as 'interactive'

R. Moody

Department of Social Sciences, Erasmus University Rotterdam, Public Administration, M7-08, PO Box 1738, 3000 DR Rotterdam, The Netherlands

J. A. van Ast $(\square)$

Department of Social Sciences, Erasmus University Rotterdam, Public Administration, M7-09, PO Box 1738, 3000 DR Rotterdam, The Netherlands

e-mail: vanast@fsw.eur.nl 
water management (Van Ast 1999). It is based on the awareness that humans are in a mutual relationship with surrounding systems, resulting in two different interactive relations: between the water manager and the actors in society (general public and different stakeholders), and between the water manager and the factors of the whole of interrelated psychical, chemical and biological components of the water system. At the end of the first decade of the 21st century, Van der Brugge (2009) concludes the Netherlands are in the middle of a transition towards integrated and interactive water management.

Knowing this, it is extremely important for water managers to have correct information about the developments within the two complex systems they have to deal with: the physical and the social system. Since these systems are strongly related, Ostrom (2007) prefers the term Social-Ecological Systems (SES). The quality of information for water governance can be considerably improved by combining the monitoring results from both SES (Hooper 2005). The digital revolution makes this realistic by integrating data of the two systems in one digital overview. New devices allow a combination of different monitoring results, regarding both the ecological and the social system, to be plotted in one geographical map. For years, water management suffered from the gap between the two worlds of information: one of the social system and one of the water system. With Geographical Information Systems (GIS) this gap can be closed. Communication advantages of GIS in terms of visualization of the current and predicted status of the SES on a common computer screen seem obvious. But can this explain the rapid introduction of GIS to the water governance agenda? In this paper we investigate the introduction of GIS in water and flood management. Under the names HIS and FLIWAS two GIS-applications were rapidly introduced in The Netherlands. With the use of agenda-setting theories we found some explanations.

\section{Geographical Information Systems and Policy Design}

Geographical Information Systems (GIS) are a type of Information and Communication Technology (ICT) because they can order, manage and integrate large quantities of spatial data and they can analyse these data and present them in a map (Meijer 2002). GIS have some features other ICT does not have. GIS make it possible to visualize spatial distributions of social entities and their characteristics and combine these with geographic spread of other social entities and their characteristics. Moreover, GIS make it possible to visualize dynamics of these entities, establish correlations between them and follow the accumulation in spatial terms of societal problems or opportunities (Snellen 2000). Also, GIS can adequately support policy design (Bekkers and Zuurmond 2005; Bekkers and Moody 2006).

There are several qualities attributed to GIS which may affect policy design (Meijer 2002; Lips et al. 2000; Bekkers and Zuurmond 2005):

1. The visibility of complex data sets in a simple map or movie is probably the most important feature of GIS-based applications. In this way non-specialists can understand expert knowledge and can assess information which is important for decision-making. Different policy alternatives can be closely evaluated and costs and benefits can be predicted more accurately.

2. Work procedures can be standardized and in this way the linking of different data sets becomes possible. With this function of control and discipline, information that was unavailable before, now can be generated. The standardization of working procedures 
also makes these procedures more controllable and transparent within and between different organizations. GIS can structure work processes and data can be collected on the course of these processes. The work process in itself becomes more transparent, which opens the possibility to adapt these processes.

3. GIS can help approach different angles of a policy problem and in this way increase the accessibility and transparency. Since GIS can calculate large quantities of data and is able to visualize issues in a comprehensive matter, a set of problems on the micro level can become clearer at the macro level.

4. GIS can be published on common Internet. In this way policy proposals become visible for everyone who is interested; making proposals and decisions become transparent to many. Electronic government can also benefit by an increase in transparency in the - already mentioned - way GIS can visualize complex data in a very simple way.

5. Communication of monitoring results can be substantially improved with GIS.

GIS applications are increasingly introduced in various policy domains. Spatial planning is enriched with all kind of information, which by using GIS is made understandable for a large group of interested actors. Due to its spatial dimension, also water management is using more and more GIS-based applications. As far as flood management is concerned, GIS has the important function of calculating predicted water levels and expected damages that are the result of the expected flooding. This role in visualising risk is important in urban planning and safety management and also has its value for the policy domains of nature and agriculture. Next to these enhancing features it must be noted that GIS also accounts for some features that can possibly limit their contructive role in policy making. Sharing information can make sure transparency is increased and organizations can work together. However, this sharing can also cause problems in terms of autonomy, privacy and the danger of making issues transparent which organizations do not want out in the open. This creates situations in which organizations are unwilling to share their information. Furthermore not all involved organizations, as well as citizens, trust the information generated. In some cases they believe the information is biased and the visualizations are leading to conclusions which might not be objective, and just being part of one organization's political agenda. This lack of trust can hinder the process of agenda setting significantly (Moody 2010).

\section{Agenda Setting}

In order to explain the rapid introduction of GIS-applications on the water management agenda, we applied a range of theories and concepts from the field of public administration. We have selected four classical models of agenda-setting of which the empirical relevance has been tested and proven in the field of GIS (Carver et al. 2000; De V. Borges and Sahay 2000; Lips et al. 2000; Meijer 2002; Moukomia 2004; Overchuk et al. 2004; Turner and Higgs 2003). Brought together, these models shed a light on why certain policy issues suddenly come in the centre of attention and even become subject of governmental action. Different models of agenda-setting are developed and applied in different settings. Well known example of policy-setting is the barrier model (Bachrach and Baratz 1970) which claims an issue needs to overcome a number of barriers (cultural, institutional etc.) before becoming a policy agenda point. Secondly the model of Cobb and Elder (1972) is used, which believes an issue can only reach agenda status if it expands to a larger public. Thirdly there is the stream model (Kingdon 1984) claiming that reaching agenda status is dependent 
on the coming together of the 'streams' of problem, policy and politics. Finally the advocacy coalition framework (Sabatier 1993) is used for explanation, which assumes agenda-status is a product of interactions between different coalitions. The basic features of these models are listed below (Table 1).

The four types of models provide the concepts which are valuable in explaining the relation between GIS and the setting of the societal agenda. In Fig. 1 we have taken the insights from these models and integrated them into one model of agenda-setting (Moody 2010). In this integrated model, agenda setting takes place in a policy sub-system: the social space in which individuals interact regarding the issue at stake (Sabatier 1993). All the actors in the policy sub-system have their own technological frame (Bijker 1995; Orlikowski 1992; Orlikowski and Gash 1994). The technological frame is the interpretive scheme of an actor that gives meaning to his social reality (Berger and Luckmann 1967; Searle 1995; Weick 2001). The technological frame holds the assumptions, expectations and knowledge about the purpose, context, importance and role of technology by a certain group of actors. This shapes the technology (Bijker 1995; Orlikowski and Gash 1994). The actors, or groups of actors, who participate in the policy sub-system all have their own issue and would like to place this issue on the agenda. Within the policy sub-system these groups might come into conflict with one another, trying to push their values forward in order to find the agenda status for an issue of their appreciation (Bachrach and Baratz 1970; Kingdon 1984). This is where power comes in. The group with a large deal of power is more likely to see a large deal of his values back into the issue reaching agenda status. A coalition with less power will see less of his beliefs back in the issue. Within the policy subsystem there are groups that will try to hinder certain issues and alternatives from reaching the agenda status. Depending on their relative amount of power they will succeed or fail in realizing a certain degree of their values (Bachrach and Baratz 1970; Cobb and Elder 1972). In order to reach a certain goal, the actors in the action arena will have to come to a consensus, with all groups involved or in case of sufficient coalition power, with a part of these groups. The larger the amount of power of an actor, the faster their issue is likely to be seen back in the final issue to reach agenda status.

Three elements that play an important role in the process of an issue becoming to reach the agenda status need attention: firstly the formal institutions, secondly the nature of the

Table 1 Features of the models of agenda-setting

\begin{tabular}{|c|c|c|c|}
\hline & Core concepts & Towards agenda status & Agenda status \\
\hline Barrier model & $\begin{array}{l}\text {-power } \\
\text {-institutions } \\
\text {-culture }\end{array}$ & $\begin{array}{l}\text { The issue must overcome barrier } \\
\text { of culture, and must pass barrier } \\
\text { of institutions. }\end{array}$ & $\begin{array}{l}\text { Overcoming the barrier of culture } \\
\text { and institutions }\end{array}$ \\
\hline Stream model & $\begin{array}{l}\text {-organized anarchy } \\
\text {-matching of problem- } \\
\text { policy-politics } \\
\text {-policy window }\end{array}$ & $\begin{array}{l}\text { The problem must be matched to } \\
\text { a policy at the right political } \\
\text { time. }\end{array}$ & $\begin{array}{l}\text { Coming together of the policy-, } \\
\text { problem- and political stream } \\
\text { when the policy window opens }\end{array}$ \\
\hline
\end{tabular}


Fig. 1 Model of agenda-setting

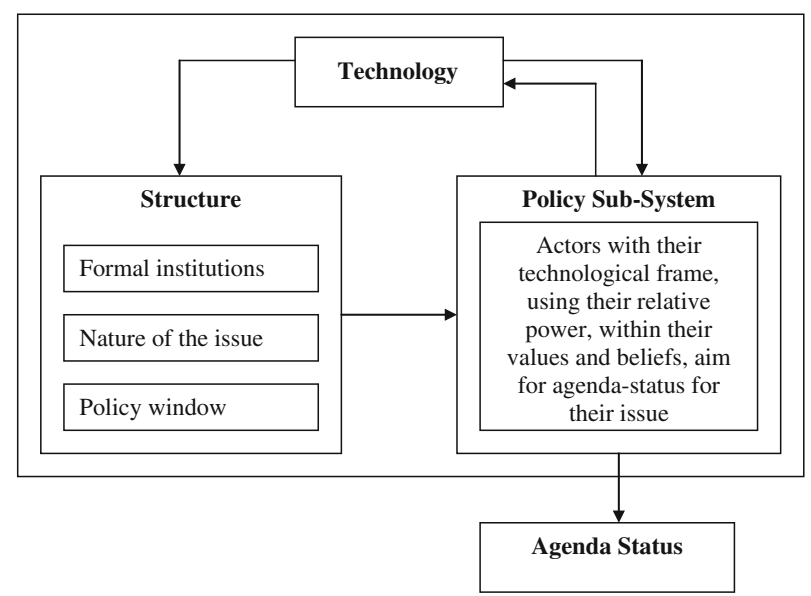

issue as opposed to content and finally the policy window. All three elements have major impact on the speed of introducing a policy issue. In the following, we elaborate on these three conditions. First the formal institutions, they consist amongst others of the formal rules and laws that account for the legal system (Bachrach and Baratz 1970). They are relevant to the policy sub-system. The actions taken in the policy sub-system in order to try bring the issue to reach agenda status, need to fit in the current legal system. The formal institutions thus determine the scope of the actions possible within the policy sub-system. The formal institutions and their procedures can make sure an issue is not able to be addressed or they can form an opportunity, when procedures are made to help an issue pass (Bachrach and Baratz 1970).

The second condition depends on the nature of the issue (Cobb and Elder 1972). This determines whether expansion to a larger public is possible and to which degree. A complex issue is less likely to expand to the general public than a fairly simple issue. When the nature of the issue hinders expansion of the issue, the advocacy coalition pushing this issue forward loses power, while it is not able to mobilize sufficient people for the cause. The nature of the issue therefore influences the interactions possible in the policy subsystem as well as the relative amount of power coalitions possess (Cobb and Elder 1972).

The third important condition for a policy issue to come to the agenda has to do with timing. The opening of a policy window can be considered to be an essential condition for agenda status (Kingdon 1984). A policy window is the opportunity to push an issue forward. When the policy window is not open at the time actors would like to push the issue forward, the issue has fewer chance of gaining agenda status. The opening of a policy window influences the scope of interactions possible in the policy sub-system. Coalitions aiming for their issue to reach agenda status have more room to negotiate when the policy window is open, additionally it will increase their relative power (Cobb and Elder 1972; Kingdon 1984).

In order to come to the agenda status, the interplay between technology, structure and the policy sub-system obtains a certain development that generally moves through four channels. First the influence of structure on the policy sub-system. As described above, this determines the scope of interaction possible. In this way the policy sub-system is influenced by the structure. Secondly the policy sub-system influences technology. Through the shaping of technology, it becomes the product of human action. Actors give meaning to the technology resulting in the artefact it is. Furthermore, humans constitute technology by 
using it by the meaning they gave to it in the process of shaping (Bijker 1995; Orlikowski 1992). Thirdly technology influences the policy sub-system, because of the technological frame. Although actors have shaped the technology and made it what it is, technology within the meaning it has been given, facilitates and constraints human action in the policy sub-system (Orlikowski 1992). In the final channel technology influences structure (Giddens 1984) through the actions in the policy sub-system. After the actors in the policy sub-system have shaped technology and closure on the meaning of technology occurs, a dominant perception of technology is established with which all groups can identify (Giddens 1984). The established technology will influence the structure, for example when new laws are made, embedded in culture. So the structure is a result of previous actions (Orlikowski 1992).

In the following we apply these concepts and conditions to the introduction of the two mentioned types of GIS in Dutch water management, in order to explain its rapid introduction.

\section{GIS: Two Examples in Dutch Water Management}

When we specifically consider the impact of GIS for water management and flood management, we can make a distinction between two main types of impact: regarding the physical system and regarding the societal system. Information about the physical system is produced in a way that water managers of various backgrounds can understand different data integrated in one simplified model. As far as the second system, the society, is concerned, interaction with the many stakeholders and the general public is also very well enhanced. GIS makes it possible to disclose complicated expertise for large groups of interested people. Communication becomes easier and the prediction in simple drawings and movies about predicted flood levels is considered to be a large advantage.

In 1993 and 1995, the high risk of flooding of a fairly large Dutch territory was the nearcrisis that made the government to realize proper information on the risks of flooding urgently had to be available. These incidents happened during a time of increasing awareness of the climate change issue and connections between flood en the greenhouse effect were easily made. But appropriate practical information was missing and a plan was made to design an application providing for this information named HIS (Hoogwater Informatie Systeem; High water Information System). Later on a plan was made to incorporate $H I S$ together with several other applications in one water management system named FLIWAS (FLood Information and WArning System). Its aim was to make sure all information was shared and combined, a smooth communication was possible and consequences in several fields were clear. Both HIS and FLIWAS are largely based on Geographical Information Systems (GIS).

The choice to include these two highly connected cases in this research is in the first place based on their similarity; they both deal with the same GIS application used for visualization and communication. Secondly the applications are new, integrating all variables important to the water management sector. Furthermore since the applications integrate a number of different applications, the influence of GIS in several fields can be investigated. This makes the analysis of their implementation in water policy more complete than when the applications would only hold one or two functions. In both case studies the method of research chosen was qualitative in nature; documents were viewed and 49 interviews with policy-makers, water management professionals, public administrators, and computer experts were conducted. The two GIS-applications HIS and FLIWAS 
are characterised below. Firstly the features of both programs are elaborated on, next the process of implementation and finally the outcome of the implementation process.

The final aim of the HIS application is to prepare for disaster. In the first place the application is able to visualize monitored water levels for the water authorities. When a water level shows to be high, a warning sign comes up. HIS places this in a logbook and is able to communicate these data to the relevant agencies. Secondly, HIS is able to predict scenarios of flooding; it will demonstrate them on an interactive map. When a dike breach occurs, it predicts when certain areas will be flooded, how high the water will be and the pressure on other dikes in order to predict whether they will breach as well. Thirdly HIS is able, on the basis of the predictions of the flooding scenarios, to calculate the damage in terms of economical and environmental damage as well as in terms of victims and evacuations.

Apart from HIS, some other applications were or are in use in Dutch water management. A main example is Infraweb, an application which is used to register calamities and inform the relevant actors. This application incorporated GIS used for communication and makes issues visible on a comprehensive map. Another application widely in use in the Netherlands is GDH (Geautomatiseerd Draaiboek Hoogwater; Automized Script High water). This is the application used by water management professionals with the aim to provide a script, a to-do list, to be applied in the case of flooding. The application is able to provide monitored water levels and is able to register this and the actions to be undertaken. Finally an application is used named VIKING. This program is used by the Dutch government in cooperation with the German government for border crossing flood issues. The VIKING application uses HIS to predict flooding but is not able to process monitored water levels, and does not include a damage calculator. Additionally it does have a communication application.

The use of many different systems has lead to the plan to incorporate all into one integrated application: FLIWAS (FLood Information and WArning System). This would prove to be a lot more convenient, since everybody would work with the same application. The aim would be to develop an application of flood management on a transnational level. It would help to increase knowledge on the risks of flooding and alert the public. It also would have to support cooperation between the water management sector and the disaster management sector. The application would incorporate all features of the applications mentioned and would be getting geographical data by satellite. The application would partially have to be available for the public in order to increase awareness of the risk of flooding. The dissemination function to professionals and to the public is a newly programmed application in FLIWAS; the script application will be taken out of the old $G H D$, for the monitoring function the HIS application would be used and InfraWeb would be build into FLIWAS to account for the logging and the messaging function. Other important elements like the flooding scenarios, the evacuation calculator and the damage calculator would be made available through the HIS application. For the VIKING system that professionals usually use, HIS was already applied; the professionals using VIKING now will help to train professionals in using FLIWAS.

Before the process of implementing HIS and FLIWAS can be understood, several partners must be distinguished. On the Dutch side, a large group of actors were involved. Firstly the Ministry of Transportation and Water Management is involved. Secondly Rijkswaterstaat (the central water agency, a department of the Ministry of Transportation and Water Management), thirdly the Water Boards (regional water authorities), and fourthly the local boards of provinces (the 12 administrative districts in the Netherlands) and cities were involved. Additionally the Ministry of Internal Affairs, responsible for the 
communication of risks and disasters, together with the Ministry of Transportation and Water Management formed the Taskforce Management Flooding (TMO). Central task was to organize flood management between the different agencies. Based on their interference with transboundary water management, also several German water managers were involved. The Hochwasserschutzzentrale Köln, (the Flood Protection Unit in Köln) and the Regierungspräsidium Karlsruhe representing six local authorities along the Rhine, were the most important.

As of yet (2010) FLIWAS has been implemented for the largest part, and HIS has been used for a while. Even though all partners generally were excited with the application, some important problems came to the surface. Where the Netherlands would like to have their InfraWeb application for communication, Germany advocated the application they already used to be incorporated in FLIWAS. Neither government was willing to give up their application and invest in training in using another application. This caused some delay in the implementation of FLIWAS.

An important complication of the implementation of FLIWAS is that the water sector is institutionally strongly dispersed. It proves to be very difficult to negotiate with one another. All the different organizations in the water sector view FLIWAS from a different angle. During technical implementation of FLIWAS, lead by consultant Royal Haskoning, it became clear the easiest way would be to use a so-called rapid application design (RAD). In this, the first draft of the application is given to users right away. This makes it possible to adapt it to their wishes, while at the same time the program is being build further. In this way users get a chance to learn how to use the application. While waiting on the final implementation of FLIWAS, most users are very content with the usability of the application.

Concerning communication with the general public, GIS-applications are not used to their full potential. Although communication about data from SES translated into comprehensive information belongs to the core of interactive water management (Van Ast 1999; Van der Brugge 2009), especially on the side of the Ministry of Internal Affairs, a culture of risk aversion appears to be a hindering factor for opening all data to the public.

\section{HIS and FLIWAS on the Agenda}

Based on the theoretical lines mentioned in section three, the cases are analyzed. Referring to the agenda-setting part, we see in the policy sub-system there are several parties to be distinguished and placed within advocacy coalitions. The Dutch Ministry of Internal Affairs, Rijkswaterstaat, the Water boards, the TMO and German Hochwasser schutzzentrale Köln form the advocacy coalition we will further name the water management professionals. Secondly the provinces, the cities in the Netherlands and the German Regierungspräsidium form an advocacy coalition which we will term the local authorities. The Ministry of Internal affairs in the Netherlands tends, in terms of values and beliefs, with their department of crisis communication to be linked to the water management professionals. But because they serve other values as well, they need to be placed in a separate advocacy coalition. Furthermore consultancy firm Royal Haskoning forms an advocacy coalition, while being the technical developer of HIS and FLIWAS. Finally the general public forms a coalition.

We see that in the policy sub-system the different advocacy coalitions function within their technological frame. The water management professionals view HIS and FLIWAS more as a visualization and calculation device, the local authorities together with the public view HIS and FLIWAS as a communication device. The Ministry of Internal Affairs 
together with Royal Haskoning recognizes both functions and does not consider one dominant over the other. Furthermore the water management professionals have a large deal of power, especially because now with HIS and FLIWAS, they can communicate the information they own more easily. It appears that most of the conflict within the policy subsystem occurs between the water management professionals and the local authorities.

Looking at the four mentioned channels through which changes take place, first of all the channel moving from the structure to the policy sub-system can be recognized. The structure mostly limits the water management professionals in pushing their ideas forward. The formal institutions do so, the nature of the issue does so, both now lessened by the usage of HIS and FLIWAS, and moreover the policy window was not available and thus hinders the water management sector in pushing their ideas forward. Even though HIS is able to show costs of flooding this, according to respondents, does not account for the same sense of urgency as an actual flood has in terms of agenda setting. This benefits those who would not like to see the water management issue being placed on the political agenda. However, with the urgency related to the floods of 1993 and 1995 a policy window was opened. Strengthened by the climate change issue, the water sector was able to get attention for the need of improved data collection and presentation, like HIS and FLIWAS can offer

Regarding the second channel, from the policy sub-system to technology, we observe that HIS and FLIWAS are shaped by the technological frames of the advocacy coalitions. Here we see that HIS and FLIWAS are both devices for communication and visualization. We see that because of the technological frames HIS and FLIWAS become an artefact used for communication, calculation and visualization. But we also see that HIS and FLIWAS serve as a tool of power for the water management sector.

The third channel concerns the channel from technology moving towards the policy subsystem. It appears that, although actors have shaped the technology and made it what it is, technology within its attributed meaning, facilitates and constraints human action in the policy sub-system. HIS and FLIWAS are perceived by water management professionals as a device to expand their issue to the larger public. By other actors it is in that way perceived as a hindering device. Next to this, HIS and FLIWAS have the power in the policy subsystem to unite the different organizations in the water management sector, making them one advocacy coalition with combined power. Additionally we see that because the water management professionals control HIS and FLIWAS, these GIS serve as a provider of power to the sector, strengthening a monopoly in terms of possession of information.

Finally the fourth channel, moving from technology towards formal institutions, is analysed. Since the actors in the policy sub-system have shaped technology, and closure on the meaning of GIS occurred, the established technology starts to influence the structure. Here we see that HIS does influence the structure to a large degree. First of all by uniting the water management sector that increasingly is perceived as one block of formal institutions. Next to this, the complicated calculations combined with the possibility to communicate this properly to policy-makers, made sure that water management professionals are taken more seriously and are more often invited to negotiations.

Another important aspect we considered was the nature of the issue. We can observe that it changed by using HIS. The issue became less complex to people and could be understood easily by many.

Apart from this, some important additional effects have been noticed. In the first place concerning formal institutions, it appears that many different actors are involved. Because of the fragmented character of the Dutch water sector, these institutions internally do not form a coalition. Secondly a culture of risk aversion is identified, which hinders full access of the public in getting information of HIS and FLIWAS. 
When looking at the outcome of the process of implementation, we see HIS is currently in use in both Germany and the Netherlands and FLIWAS has been implemented for the largest part. The autonomy problem, in which Germany and the Netherlands both want to use their own system, could not be solved. Germany puts its own application in FLIWAS and the Netherlands remain using InfraWeb.

In terms of the added value of GIS in HIS and FLIWAS, most organizations dealing with water agree: by using maps and movies it becomes easier to communicate with policymakers. Not only to prevent flooding but also during a flood it is possible to explain what is likely to happen in the coming hours. Partially due to this visualization function the communication with policy-makers, stakeholders and the general public became much easier. All interviewed parties agree that HIS and FLIWAS, by using the GIS interface, make the public able to be more aware of the risks of flooding. Although this does increase the transparency on the possible scenarios for preventing flooding and to explain current situations, it must be noted that this transparency should not be considered complete. The visualisations as such do not explain or state the implicit assumptions made in the model or possible margins of error. Transparency does increase because now non-experts can understand what is going on, but this transparency might be limited for they are not aware of the underlying assumptions. Misinterpretation of the GIS-visualisations is always a risk that has seriously to be taken care for.

Furthermore, we can see HIS and FLIWAS have had a profound impact on agendasetting of flood management and the overall policy design within the water management framework. Because HIS and FLIWAS are able to let professionals try out scenarios and then predict consequences, several instances of dike reinforcement were placed on the agenda and implemented after HIS has predicted dangerous scenarios. In this way, HIS and FLIWAS are becoming important instruments for spatial planning. Governments can now clearly see which part of their territory is at risk. This is important input for decisionmaking about building areas and additional routes for evacuation.

\section{Discussion and Conclusions}

We now can draw conclusions about the reasons for the rapid introduction of GIS in the water management sector. In the first place the influence of GIS becomes visible when looking at the communication function. This is threefold; primarily we see that the visualization function of HIS and FLIWAS contributes to agenda-setting because water issues can be communicated in a clearer way to policy-makers. Secondly communication between the water management sector and other sectors becomes easier. Through the interactive movies and maps, water management professionals can make potential problems clearer to other specialists. This benefits communication with other policy-sectors to a large degree. Finally it becomes less difficult to involve the general public, since it GIS makes it much easier to communicate water issues to them. These factors all contribute to their rapid implementation.

An important second factor for rapid introduction results from the increasing strength the water sector obtained during the implementation of HIS and FLIWAS. The change to one integrated communication device contributed to the ability of the water management sector to function in the process of agenda-setting as one unitary actor. Therefore HIS and FLIWAS certainly promote the integration process in the water management sector and exert more power to water management in the policy arena. The sectors stronger position made it possible to further foster implementation of GIS, resulting in a continuing increase of power, consequently strengthening this cyclic process of rapid implementation. By using 
HIS and FLIWAS, a fair amount of power in the agenda-setting process flows from local and provincial authorities to the water management sector. This can be explained by the monopoly position of the water management sector with respect to detailed information on flood risks. Through calculation and the power to visualize and communicate situations, clearly the water management sector is able to place issues on the agenda.

An intervening variable concerns the increase in transparency. Work processes are considerably more transparent, since all water management organizations work with the same application. But also the policy problem itself can become more transparent because $H I S$ is able to make necessary calculations. Through the calculation function of HIS and FLIWAS the water management sector has a powerful tool to demonstrate what effects result from certain actions - or the lack of these actions. It can for example force policymakers to place flood risks on the agenda.

Surely, the urgency of high water levels of 1993 and 1995 in the Netherlands opened a policy window for the government to fairly quick allocate the means for the implementation of HIS and FLIWAS. Since the rich history of Dutch water management caused the water sector to be very fragmented, communication between different water management organizations was poor. Too many interests were at stake and too many organizations were involved. Initially fragmentation in the water sector prevented operating as an influential actor, hindering the agenda-setting influence of HIS and FLIWAS to be exerted to a large degree. But, by the use of HIS and FLIWAS the actors in the water management sector are forced to organize themselves and form a block by which they can exert this influence.

In terms of theory it may be concluded that agenda setting can well be used to contribute to an explanation of the speed of implementation processes. Of course the results have to be considered in relation to competing policy issues that are at stake. But our effort to combine and integrate separate insights of different models allowed us to assess the rapid introduction of GIS. Where the structure of the advocacy coalition framework helps to analyse the overall surroundings and the different actors, Kingdons model provides us with an opportunity to explain the policy window. For the barrier model and Cobb and Elders model, they account for the way in which power is used within the model. It is our assumption that our model can be used for the analysis of the impact of technology in other cases as well, since the model shows a large deal of explanatory capacity.

In this way, public administration theory can help analyzing cases in the water management sector. Policy-makers can learn that when they urgently need to implement policy innovations rapidly, they could focus on increasing and simplifying communication by an increase of transparency, and when possible by using visualization and calculation potential. Besides, a promoting factor like a power relations change in the agenda-setting process in the way that the specialised sector gains influence, could be enhanced. Once established as an artefact, HIS and FLIWAS could influence the structure by uniting the water management sector to an influential block in the formal institutions. Other policy innovation could have this effect as well. In our case the calculation ability combined with the possibility to communicate the results properly to policy-makers, made sure that water management professionals were taken more seriously and were more often invited to negotiations. These kinds of factors are relevant in all policy introductions.

Although GIS strongly promote agenda-setting for the water issue, their full potential can only be acquired when a new policy window is available for opening. This could happen for example when another flood would harm The Netherlands in times of climate urgency. As soon as that is the case, a further improvement of decision-making regarding the whole of the SES, the ecological ánd the social system, can be integrated, and interactive water management becomes reality. 
Open Access This article is distributed under the terms of the Creative Commons Attribution Noncommercial License which permits any noncommercial use, distribution, and reproduction in any medium, provided the original author(s) and source are credited.

\section{References}

Allen, TFH, Bandursky BL, King AW (1992) The ecosystem approach: theory and ecosystem integrity, International Joint Commission United Staes and Canada (Washington D.C. USA)

Bachrach P, Baratz M (1970) Power and poverty. Theory and practice. Oxford University Press, New York

Bekkers VJJM, Moody RFI (2006) Geographical Information Systems and the policy formulation process: the emergence of a reversed mixed scanning mode? In: Bekkers VJJM, van Duivenboden H, Thaens M (eds) Information and communication technology and public innovation: assessing the ICT-driven modernization of public administration. Ios, Amsterdam, pp 103-120

Bekkers V, Zuurmond A (2005) Achtergronden en eigenschappen van ICT. In: Lips M, Bekkers V, Zuurmond A (eds) ICT en openbaar bestuur. Implicaties en uitdagingen van technologische toepassingen voor de overheid. Lemma BV, Utrecht, pp 47-72

Berger PL, Luckmann T (1967) The social construction of reality. A treatise in the sociology of knowledge. Anchor Books, New York

Bijker WE (1995) Of bicycles, bakelites, and bulbs. Toward a theory of sociotechnical change. MIT, Cambridge

Carver S, Evans A, Kingston R, Turton I (2000) Accessing geographical information systems over the world wide web: improving public participation in environmental decision making. Inform Infrastruct Pol 6:157-170

Cobb RW, Elder CD (1972) Participation in American politics. The dynamics of agenda-building. The John Hopkins University Press, Baltimore

De V. Borges KA, Sahay S (2000) GIS for the public sector: experiences from the city of Belo Horizonte, Brazil. Inform Infrastruct Pol 6:139-155

Giddens A (1984) The constitution of society. Outline of the theory of structuration. University of California Press, Berkely

Holling CS (1973) Resilience and stability of ecological systems. Annu Rev Ecol Systemat 4:1-23

Hooper BP (2005) Integrated river basin governance: Learning from international experience. IWA, London Seattle

Kingdon JW (1984) Agendas, alternatives and public policies. HarperCollins College Publishers, New York

Lips M, Boogers M, Weterings R (2000) Reinventing territory in dutch local government: experiences with the development and implementation of GIS in the Amsterdam Region. Inform Infrastruct Pol 6:171183

Meijer A (2002) Geographical information systems and public accountability. Inform Pol 7:39-47

Moody RFI (2010) Mapping power. Geographical information systems, agenda-setting and policy design. Erasmus University, Rotterdam

Moukomia S (2004) Rapid response spatial information systems: avian influenza in Thailand. Geo-Informatics and Space Technology Development Agency, Bangkok

Ollsson P, Folke C, Berkes F (2004) Adaptive comanagement for building resilience in social-ecological systems. Environ Manag 3:75-90

Orlikowski WJ (1992) The duality of Technology: rethinking the concept of technology in organizations. Organ Sci 3:398-427

Orlikowski WJ, Gash DC (1994) Technological frames: making sense of information technology in organizations. ACM Trans Inf Syst 12:174-207

Ostrom E (2007) A diagnostic approach for going beyond panaceas. PNAS Proc Natl Acad Sci U S A 1004:15181-15187

Overchuk AL, Hansen L, Hansen NH (2004) Developing a farm land distribution model in Russia. Federal Agency for the Immovable Property, Cadastre, Russia

Sabatier PA (1993) Policy change over a decade or more. In: Sabatier PA, Jenkins-Smith HC (eds) Policy change and learning. An advocacy coalition approach. Westview, Boulder

Saeijs HLF (1991) Integrated water management. A new concept: from treating of symptoms towards a controlled ecosystem management in the Dutch delta. Landsc Urban Plann 20:245-255

Searle JR (1995) The construction of social reality. Penguin, London

Snellen IThM (2000) Territorialising governance and the state: policy dimensions of geographic information systems. In: Information infrastructure and policy, vol. 6. IOS Press, Amsterdam, The Netherlands, pp. $131-138$ 
Turner P, Higgs G (2003) The use and management of geographic information in local e-government in the UK. Information Polity 8:151-165

Van Ast JA (1999) Trends towards interactive water management; developments in international river basin management. Phys Chem Earth 24:597-602

Van der Brugge (2009) Transition dynamics in social ecological systems: the case of Dutch water management, Dissertation Erasmus University Rotterdam. Rotterdam, Erasmus University

Weick KE (2001) Making sense of the organization. Blackwell, Oxford 